Nils Kaienburg

\title{
Compliance in High Profile-Fällen der WTO
}

\author{
Legal Case Management am Beispiel des Airbus-Boeing-Falls
}

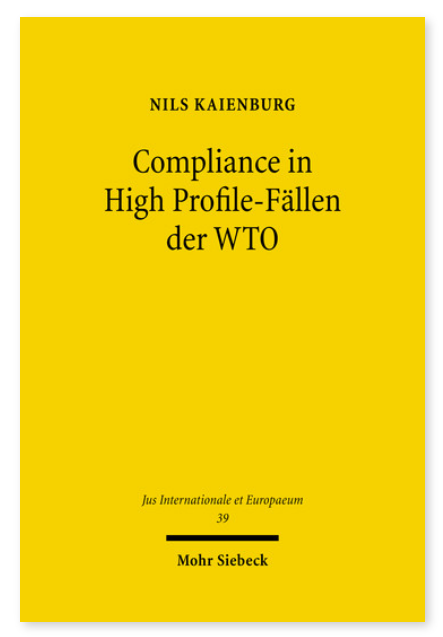

2010. XXI, 358 Seiten. JusIntEu 39

ISBN 978-3-16-151178-3

DOI 10.1628/978-3-16-151178-3

eBook PDF $89,00 €$

ISBN 978-3-16-150439-6

fadengeheftete Broschur 89,00€
Das WTO-Streitbeilegungsverfahren zeichnet sich durch insgesamt hohe Befolgungszahlen aus. Bei den Mitgliedstaaten herrscht deshalb große Zufriedenheit. Dies gilt jedoch nicht für die so genannten High Profile-Fälle, wozu insbesondere der Airbus-Boeing-Streit zählt. Nils Kaienburg untersucht diesen bis heute größten und komplexesten Fall seit Bestehen der WTO und zeigt exemplarisch Möglichkeiten auf, wie derartig konfliktgeladene Fälle über ein verbessertes Streitbeilegungsverfahren gehandhabt werden können. Dazu dient das im vorliegenden Buch entwickelte Konzept des Legal Case Managements, das in erster Linie ein optimiertes Mediationsverfahren beinhaltet. Eine solche Herangehensweise erscheint gerade in High ProfileFällen als notwendig, da diese das WTO-Streitbeilegungsverfahren als Ganzes unterminieren können.

Nils Kaienburg Geboren 1978, Studium der Rechtswissenschaft in Hannover; 2005 LL.M. an der Victoria University of Wellington; 2009 Promotion; derzeit Referendar im OLG-Bezirk Celle.

Jetzt bestellen:

https://mohrsiebeck.com/buch/compliance-in-high-profile-faellen-der-wto-9783161511783?no_cache=1 order@mohrsiebeck.com

Telefon: +49 (0)7071-923-17

Telefax: +49 (0)7071-51104 